\title{
TRATAMENTO DO CÂNCER GINECOLÓGICO VISANDO A PRESERVAÇÃO DA FERTILIDADE
}

CATEGORIA: CIRÚRGICO

FACULDADE DE MEDICINA

CENTRO UNIVERSITÁRIO SÃo CAMILO

PAVÃO, F T'1- Endereço Rua Enrico de Martino, número 330

Telefone: (11) 96132-5934 - Email: tonettin31@gmail.com.

Pavão, FT $^{1}$; Rodrigues, ${ }^{1}$; Rocha,KS ${ }^{1} ;$ Pereira,, $\mathbf{M M}^{2}$; Vilarino,FL ${ }^{2}$.

1. Discente do Centro Universitário São Camilo 2. Docente do Centro Universitário São Camilo 


\section{TRATAMENTO DO CÂNCER GINECOLÓGICO VISANDO A PRESERVAÇÃO DA FERTILIDADE}

PAVÃO, FT ${ }^{1}$; RODRIGUES, ${ }^{1}$; ROCHA,KS ${ }^{1}$; PEREIRA,MM ${ }^{2}$; VILARINO,FL ${ }^{2}$.

DESCRITORES: "Fertility Preservation" AND “Genital Neoplasms, Female 


\section{TRATAMENTO DO CÂNCER GINECOLÓGICO VISANDO A PRESERVAÇÃO DA FERTILIDADE}

\section{RESUMO}

INTRODUÇÃO: Os recentes avanços na oncologia referentes ao diagnóstico precoce e à eficácia dos tratamentos de mulheres com câncer ginecológico promovem melhora no prognóstico em pacientes na menacme ${ }^{2}$. Anualmente, há um acréscimo de $0,3 \%$ do número de casos de câncer ginecológico no mundo; no entanto, o índice de cura aumenta $0,6 \%$ o que desperta o interesse quanto a preservação da fertilidade dessas mulheres ${ }^{1}$.

OBJETIVO: Atualização quanto ao tratamento do câncer ginecológico visando a preservação da fertilidade.

MÉTODOS: Foi realizada revisão sistemática da literatura nas bases de dados PubMed e Scielo, com termos; "(Fertility Preservation)" AND "Genital Neoplasms, Female". Total de 456 artigos encontrados. Após aplicar os critérios de inclusão: disponibilidade no idioma inglês, adequação ao tema proposto e publicação de 2013 a 2018; excluindo-se artigos de revisão e relatos de caso. Foram selecionados 34 estudos.

DISCUSSÃO: Calcula-se que, anualmente, 650 mil mulheres são atingidas por câncer ginecológico invasivo e dessas $8 \%$ têm menos de 40 anos. Durante o tratamento, a radioterapia, quando for em região pélvica, poderá danificar os ovários, dependendo do tamanho e da localização do tumor e da intensidade da irradiação. O mesmo pode ocorrer com a quimioterapia, dependendo das drogas utilizadas e das doses necessárias. As cirurgias radicais totais são, em sua maioria, a melhor opção; o que pode macular o futuro fértil destas mulheres. Os estudos destacaram principais métodos para preservação da fertilidade feminina; 26 artigos descreveram a cirurgia conservadora como técnica alternativa à histerectomia e ooforectomia bilateral em pacientes jovens. 8 outros artigos apontaram como manejo poupador de fertilidade hormonal, o uso de progesterona oral (acetato de medroxiprogesterona (MPA) ou acetato de megestrol (MA)), para menor impacto sobre a fertilidade; além do diagnóstico precoce.

CONCLUSÃO: Apesar do avanço das técnicas de tratamento do câncer ginecológico com maior probabilidade de cura nos últimos anos; o diagnóstico precoce é fundamental para o sucesso da preservação da fertilidade feminina. Foi possível identificar que $46,43 \%$ foi a taxa de sucesso para gestações pós tratamento oncológico, desde que associada ao diagnóstico precoce e sem associação à diminuição da sobrevida das pacientes quando utilizado métodos como cirurgia conservadora ou tratamento hormonal com MPA ou MA.

DESCRITORES: "Fertility Preservation" and "Genital Neoplasms, Female 


\section{TRATAMENTO DO CÂNCER GINECOLÓGICO VISANDO A PRESERVAÇÃO DA FERTILIDADE}

\section{INTRODUÇÃO}

Os recentes avanços na área da oncologia referentes ao diagnóstico precoce e à eficácia dos tratamentos de mulheres com câncer ginecológico (Vulva, Colo de Útero, endométrio e Ovário) promovem aumento dos índices de cura e melhor prognóstico em considerável número de pacientes jovens, muitas dessas em idade reprodutiva de 25 a 45 anos ${ }^{11}$. Um aspecto que chama a atenção, é que há o registro, anualmente, de um acréscimo de $0,3 \%$ do número de casos de câncer ginecológico no mundo, isto é, 650 mil mulheres no mundo são atingidas por câncer ginecológico invasivo e dessas $8 \%$ têm menos de 40 anos $^{21}$. Por outro lado, o índice de cura desses vem aumentando em $0,6 \%$ ao ano ${ }^{12}$, o que desperta o interesse quanto a qualidade de vida das pacientes após o tratamento; destacando-se à preservação da fertilidade dessas mulheres.

\section{OBJETIVO}

Abordar os métodos de tratamento do câncer ginecológico visando a preservação da fertilidade.

\section{METODOLOGIA}

Foi realizada revisão sistemática da literatura nas bases de dados PubMed e Scielo, utilizando os termos; "Fertility Preservation" AND "Genital Neoplasms, Female", entre 2013 e 2018. Um total de 456 artigos foram encontrados. Após aplicar os critérios de exclusão: artigos de revisão e relatos de caso, foram selecionados um total de 34 estudos.

\section{RESULTADOS:}

\begin{tabular}{|l|l|l|l|l|}
\hline Nome & Ano & $\begin{array}{l}\text { Tipo de } \\
\text { Estudo }\end{array}$ & Amostra & Resultados \\
\hline $\begin{array}{l}\text { 1. Maintenance } \\
\text { hormonal } \\
\text { therapy after } \\
\text { treatment } \\
\text { with } \\
\text { medroxyprogesterone } \\
\begin{array}{l}\text { acetate for patients } \\
\text { with } \\
\text { atypical polypoid } \\
\text { adenomyoma }\end{array}\end{array}$ & 2018 & $\begin{array}{l}\text { Estudo } \\
\text { retrospectivo }\end{array}$ & $\begin{array}{l}\text { 18 pacientes } \\
\text { foram tratados } \\
\text { por um período } \\
\text { de observação } \\
\text { meses }\end{array}$ & $\begin{array}{l}\text { Durante a terapia de } \\
\text { manutenção, nenhum paciente } \\
\text { teve recaída de adenomioma } \\
\text { polipóide atípico (APA). } \\
\text { Onze pacientes sem terapia de } \\
\text { manutenção foram submetidos } \\
\text { à histerectomia, e nove deles } \\
\text { desenvolveram câncer } \\
\text { endometrial bem diferenciado. }\end{array}$ \\
\hline $\begin{array}{l}\text { 2.Long-term safety of } \\
\text { fertility sparing } \\
\text { surgery in early stage }\end{array}$ & 2015 & $\begin{array}{l}\text { Estudo } \\
\text { comparativo }\end{array}$ & 307 pacientes & $\begin{array}{l}\text { 307 pacientes tiveram a } \\
\text { cirurgia para eEOC (câncer } \\
\text { de ovário epitelial de baixo }\end{array}$ \\
\hline
\end{tabular}




\begin{tabular}{|c|c|c|c|c|}
\hline $\begin{array}{l}\text { ovarian cancer: } \\
\text { comparison to } \\
\text { standard radical } \\
\text { surgical procedures. }\end{array}$ & & & & $\begin{array}{l}\text { grau (G1-2) em estágio } \\
\text { inicial ): } 70 \text { (22,8\%) e } 237 \\
(77,2 \%) \text { mulheres tiveram } \\
\text { cirurgia poupadora de } \\
\text { fertilidade (FSS) e } \\
\text { estadiamento abrangente } \\
\text { radical (RCS), } \\
\text { respectivamente. } \\
\text { O FSS defende a eficácia } \\
\text { oncológica do RCS, } \\
\text { preservando as funções } \\
\text { reprodutivas e } \\
\text { endócrinas. FSS não aumenta } \\
\text { o risco de recorrência entre os } \\
\text { pacientes de alto risco eEOC }\end{array}$ \\
\hline $\begin{array}{l}\text { 3.Safety of ovarian } \\
\text { conservation and } \\
\text { fertility preservation } \\
\text { in advanced } \\
\text { borderline ovarian } \\
\text { tumors. }\end{array}$ & 2015 & $\begin{array}{l}\text { Estudo } \\
\text { histórico de } \\
\text { coorte }\end{array}$ & 59 pacientes & $\begin{array}{l}\text { A maioria dos tumores (51, } \\
84,4 \%) \text { apresentava histologia } \\
\text { serosa. Vinte e sete pacientes } \\
(45,8 \%) \text { desenvolveram } \\
\text { recidivas e } 6(10 \%) \text { morreram } \\
\text { de sua doença. } \\
\text { De } 44 \text { mulheres } \leq 40 \text { anos, } \\
33(75 \%) \text { tiveram um } \\
\text { procedimento poupador de } \\
\text { fertilidade. A preservação } \\
\text { da fertilidade não foi } \\
\text { associada à recorrência da } \\
\text { doença. } \\
\text { Total de } 34 \text { gestações e } 26 \\
\text { nascidos vivos foram } \\
\text { documentados entre } 21 \\
\text { pacientes que tentaram } \\
\text { engravidar. }\end{array}$ \\
\hline $\begin{array}{l}\text { 4.Preservation of the } \\
\text { fertility and the } \\
\text { ovaries in women } \\
\text { with benign adnexal } \\
\text { tumors. }\end{array}$ & 2015 & $\begin{array}{l}\text { Estudo } \\
\text { observacional }\end{array}$ & $\begin{array}{l}206 \text { mulheres } \\
\text { com tumores } \\
\text { anexiais } \\
\text { benignos }\end{array}$ & $\begin{array}{l}120(58 \%) \text { estavam na } \\
\text { pré-menopausa e } 86(42 \%) \text { na } \\
\text { pós-menopausa. } \\
\text { Entre as pacientes com } \leq 35 \\
\text { anos, } 26(57 \%) \text { foram } \\
\text { submetidas à tumorectomia e } \\
18(39 \%) \text { a anexectomia } \\
\text { unilateral com preservação do } \\
\text { útero e anexo contralateral. } \\
\text { Mulheres com } \leq 35 \text { anos foram } \\
\text { mais frequentemente operadas } \\
\text { por laparoscopia que esteve } \\
\text { associada a maior taxa de } \\
\text { preservação de fertilidade } \\
\text { quando comparada com a } \\
\text { laparotomia }\end{array}$ \\
\hline
\end{tabular}




\begin{tabular}{|c|c|c|c|c|}
\hline $\begin{array}{l}\text { 5. Ovarian } \\
\text { preservation in young } \\
\text { patients with stage I } \\
\text { cervical } \\
\text { adenocarcinoma: a } \\
\text { surveillance, } \\
\text { epidemiology, and } \\
\text { end results study. }\end{array}$ & 2014 & $\begin{array}{l}\text { Estudo } \\
\text { comparativo }\end{array}$ & $\begin{array}{l}1639 \text { mulheres } \\
\text { com } 45 \text { anos ou } \\
\text { menos com } \\
\text { adenocarcinom } \\
\text { a cervical } \\
\text { estágio I e } \\
\text { carcinoma } \\
\text { adenoescamoso }\end{array}$ & $\begin{array}{l}1062 \text { mulheres }(64,8 \%) \text { que } \\
\text { foram submetidas a } \\
\text { ooforectomia e } 577 \text { mulheres } \\
(35,2 \%) \text { que tiveram a } \\
\text { preservação do ovário no } \\
\text { momento da histerectomia. } \\
\text { Idade mais jovem, diagnóstico } \\
\text { recente, baixo grau e menor } \\
\text { tumor, população branca, bem } \\
\text { como menor chance de sofrer } \\
\text { linfadenectomia e radioterapia } \\
\text { adjuvante foram associados à } \\
\text { preservação ovariana. } \\
\text { A preservação ovariana não } \\
\text { teve nenhum efeito sobre a } \\
\text { sobrevida específica do } \\
\text { câncer . } \\
\end{array}$ \\
\hline $\begin{array}{l}\text { 6. Possibilities of } \\
\text { fertility preservation } \\
\text { in young patients } \\
\text { with ovarian cancer. }\end{array}$ & 2014 & $\begin{array}{l}\text { Estudo } \\
\text { retrospectivo }\end{array}$ & $\begin{array}{l}51 \text { pacientes } \\
\text { com idade } \\
\text { inferior a } 40 \\
\text { anos com um } \\
\text { tumor maligno } \\
\text { de ovário }\end{array}$ & $\begin{array}{l}21(41,2 \%) \text { pacientes fizeram } \\
\text { à cirurgia de preservação da } \\
\text { fertilidade primária. } 3 \text { delas } \\
(5,9 \%) \text { necessitaram de } \\
\text { cirurgia secundária de câncer } \\
\text { de ovário devido à recidiva, } \\
\text { recaída inoperável foi } \\
\text { encontrada em } 1 \text { paciente } \\
(2 \%) \text { durante a cirurgia. } 30 \\
\text { mulheres (58,8\%) foram } \\
\text { submetidas principalmente à } \\
\text { histerectomia total e à } \\
\text { adnexectomia bilateral devido } \\
\text { a um estágio mais alto da } \\
\text { FIGO (Sistema de } \\
\text { Estadiamento da Federação } \\
\text { Internacional de Ginecologia e } \\
\text { Obstetrícia) ou planejamento } \\
\text { familiar completo. } \\
\end{array}$ \\
\hline $\begin{array}{l}\text { 7. Fertility-preserving } \\
\text { treatment in young } \\
\text { women with } \\
\text { endometrial } \\
\text { adenocarcinoma: a } \\
\text { long-term cohort } \\
\text { study. }\end{array}$ & 2014 & $\begin{array}{l}\text { Estudo de } \\
\text { Coorte }\end{array}$ & $\begin{array}{l}37 \text { mulheres } \\
\text { jovens com } \\
\text { carcinoma } \\
\text { endometrial } \\
\text { endometrioide } \\
\text { grau } 1 \text { na fase } \\
\text { IA presumida }\end{array}$ & $\begin{array}{l}\text { Resposta completa com } \\
\text { duração superior a } 6 \text { meses } \\
\text { foi alcançada em } 30(81,1 \%) \\
\text { mulheres. } \\
\text { Das } 30 \text { mulheres que tiveram } \\
\text { um CR, } 15(50,0 \%) \\
\text { apresentaram recidiva da } \\
\text { doença. } \\
\text { Demonstra a viabilidade da } \\
\text { terapia baseada em acetato de } \\
\text { megestrol em altas doses para } \\
\text { a preservação da } \\
\text { fertilidade. O risco }\end{array}$ \\
\hline
\end{tabular}




\begin{tabular}{|c|c|c|c|c|}
\hline & & & & $\begin{array}{l}\text { substancial de recidivas } \\
\text { tardias destaca a necessidade } \\
\text { de estudos de } \\
\text { acompanhamento a longo } \\
\text { prazo de grandes amostras } \\
\text { com assinaturas moleculares } \\
\text { detalhadas de tumores e } \\
\text { hospedeiros. }\end{array}$ \\
\hline $\begin{array}{l}\text { 8. Outcome of } \\
\text { fertility preserving } \\
\text { surgery in early stage } \\
\text { ovarian cancer. }\end{array}$ & 2013 & $\begin{array}{l}\text { la } \\
\text { estudo } \\
\text { prospectivo } \\
\text { não } \\
\text { randomizado }\end{array}$ & $\begin{array}{l}150 \text { pacientes } \\
\text { com suspeita } \\
\text { de massa } \\
\text { ovariana } \\
\text { maligna } \\
\text { precoce }\end{array}$ & $\begin{array}{l}\text { Apenas 32/150 (21,3\%) } \\
\text { pacientes apresentaram } \\
\text { estágio IA, G1 ou G2, câncer } \\
\text { de ovário epitelial. } \\
\text { Todos os pacientes tinham } \\
\text { tumores unilaterais; } 26 \\
(81,25 \%) \text { pacientes } \\
\text { apresentavam o G1 e } 6 \\
(18,75 \%) \text { pacientes } \\
\text { apresentavam tumores do G2; } \\
24 / 32(75,0 \%) \text { tumores eram } \\
\text { serosos, 6/32 }(18,7 \%) \text { eram } \\
\text { mucinosos e } 2 / 32(6,2 \%) \text { eram } \\
\text { endometrioides, e nenhum era } \\
\text { do tipo celular claro . } \\
\text { A cirurgia de preservação da } \\
\text { fertilidade pode ser } \\
\text { considerada uma estratégia de } \\
\text { tratamento seguro em } \\
\text { pacientes com carcinoma } \\
\text { ovariano estágio IA, G1 ou } \\
\text { G2. }\end{array}$ \\
\hline $\begin{array}{l}\text { 9. Fertility outcomes } \\
\text { of patients with early } \\
\text { stage endometrial } \\
\text { carcinoma. }\end{array}$ & 2014 & $\begin{array}{l}\text { Estudo } \\
\text { longitudinal }\end{array}$ & $\begin{array}{l}9 \text { pacientes } \\
\text { diagnosticadas } \\
\text { com carcinoma } \\
\text { endometrial em } \\
\text { estágio inicial e } \\
\text { que queriam } \\
\text { poupar a } \\
\text { fertilidade }\end{array}$ & $\begin{array}{l}\text { Em todos os pacientes, o } \\
\text { carcinoma apresentava pólipos } \\
\text { ressecados pela } \\
\text { histeroscopia. Após serem } \\
\text { informados sobre as terapias } \\
\text { cirúrgicas e médicas, } \\
\text { quatro pacientes preferiram a } \\
\text { cirurgia e cinco preferiram o } \\
\text { tratamento médico. } \\
\text { O tratamento conservador do } \\
\text { carcinoma endometrial é } \\
\text { seguro na maioria dos } \\
\text { casos. No entanto, } \\
\text { os pacientes devem estar bem } \\
\text { informados sobre os riscos do } \\
\text { tratamento conservador, pois } \\
\text { atrasar o tratamento definitivo } \\
\text { às vezes piora o prognóstico. }\end{array}$ \\
\hline
\end{tabular}




\begin{tabular}{|c|c|c|c|c|}
\hline $\begin{array}{l}\text { 10. Safety of ovarian } \\
\text { preservation in young } \\
\text { patients with } \\
\text { early-stage } \\
\text { endometrial cancer: a } \\
\text { retrospective study } \\
\text { and meta-analysis. }\end{array}$ & 2013 & $\begin{array}{l}\text { Estudo } \\
\text { retrospectivo e } \\
\text { meta-análise. }\end{array}$ & $\begin{array}{l}203 \text { pacientes } \\
\text { com } \\
\text { diagnóstico } \\
\text { de câncer } \\
\text { endometrial } \\
\text { ( } \leq 45 \text { anos) }\end{array}$ & $\begin{array}{l}169 \text { pacientes }(83,3 \%) \text { foram } \\
\text { submetidos a } \\
\text { salpingo-ooforectomia } \\
\text { bilateral, } 20 \text { pacientes tiveram } \\
\text { ambos os ovários preservados } \\
\text { e } 14 \text { pacientes tiveram um } \\
\text { único ovário preservado. } \\
\text { A preservação ovariana não } \\
\text { tem impacto estatisticamente } \\
\text { significativo na sobrevida } \\
\text { global das pacientes jovens } \\
\text { com câncer endometrial em } \\
\text { estágio inicial. }\end{array}$ \\
\hline $\begin{array}{l}\text { 11. A retrospective } \\
\text { study of tumor and } \\
\text { fertility outcomes } \\
\text { after fertility-sparing } \\
\text { surgical treatment of } \\
\text { patients with } \\
\text { borderline ovarian } \\
\text { tumors. }\end{array}$ & 2017 & $\begin{array}{l}\text { Estudo } \\
\text { retrospectivo }\end{array}$ & $\begin{array}{l}119 \text { pacientes } \\
\text { com tumor } \\
\text { ovariano } \\
\text { limítrofe } \\
\text { (BOT) }\end{array}$ & $\begin{array}{l}55 \text { pacientes foram } \\
\text { submetidos à cirurgia de } \\
\text { fertilidade. A mediana de } \\
\text { idade foi de } 43 \text { anos. } \\
\text { Foram } 103 \text { pacientes } \\
(86,55 \%) \text { no estágio I e } \\
16 \text { pacientes }(13,45 \%) \text { no } \\
\text { estágio } \Pi \text { II acima. } \\
13 \text { pacientes recorreram e } \\
3 \text { pacientes morreram. } \\
\end{array}$ \\
\hline $\begin{array}{l}\text { 12.Fertility-preservin } \\
\text { g surgery for } \\
\text { advanced stage } \\
\text { ovarian germ cell } \\
\text { tumors. }\end{array}$ & 2017 & $\begin{array}{l}\text { Estudo de } \\
\text { coorte }\end{array}$ & $\begin{array}{l}526 \text { pacientes } \\
\text { com <40 anos } \\
\text { diagnosticadas } \\
\text { com tumor } \\
\text { maligno de } \\
\text { células } \\
\text { germinativas } \\
\text { ovarianas } \\
\text { (MOGCT) de } \\
\text { estágio } \\
\text { avançado } \\
\text { (estágio II-IV) }\end{array}$ & $\begin{array}{l}\text { As mulheres que tiveram uma } \\
\text { histerectomia eram mais } \\
\text { velhas (mediana de idade } \\
30,5 \text { vs } 20 \text { anos, } p<0,001 \text { ) e } \\
\text { mais propensas a apresentar } \\
\text { tumores bilaterais. Não foram } \\
\text { observadas diferenças com } \\
\text { base na histologia do tumor. } \\
\text { A preservação uterina não foi } \\
\text { associada à diminuição da } \\
\text { sobrevida e deve ser } \\
\text { considerada em mulheres } \\
\text { com TCG em estágio } \\
\text { avançado interessadas } \\
\text { em fertilidade futura }\end{array}$ \\
\hline $\begin{array}{l}\text { 13. Safety of } \\
\text { Fertility-Sparing } \\
\text { Surgery for } \\
\text { Premenopausal } \\
\text { Women With Sex } \\
\text { Cord-Stromal } \\
\text { Tumors Confined to } \\
\text { the Ovary. }\end{array}$ & 2017 & $\begin{array}{l}\text { Estudo de } \\
\text { coorte }\end{array}$ & $\begin{array}{l}255 \text { mulheres } \\
\text { com idade } \\
\text { entre } 18-49 \\
\text { anos e } \\
\text { diagnosticada } \\
\text { com tumor } \\
\text { estromal do } \\
\text { cordão maligno } \\
\text { do sexo } \\
\text { (SCSTs) } \\
\text { confinados ao } \\
\text { ovário }\end{array}$ & $\begin{array}{l}161(63,1 \%) \text { foram } \\
\text { submetidos à cirurgia que } \\
\text { poupa de fertilidade (SSF), } \\
\text { enquanto } 94 \text { ( } 36,9 \%) \text { tiveram } \\
\text { cirurgia definitiva } \\
\text { (salpingo-ooforectomia } \\
\text { bilateral e histerectomia). } \\
\text { SSF esteve associada } \\
\text { apenas a pior sobrevida } \\
\text { a longo prazo específica } \\
\text { do câncer em comparação } \\
\text { com a cirurgia } \\
\text { definitiva. Mulheres } \\
\text { submetidas a FSS para }\end{array}$ \\
\hline
\end{tabular}




\begin{tabular}{|c|c|c|c|c|}
\hline & & & & $\begin{array}{l}\text { SCSTs em estágio inicial } \\
\text { devem ser amplamente } \\
\text { aconselhadas e monitoradas } \\
\text { de perto. }\end{array}$ \\
\hline $\begin{array}{l}\text { 14. Fertility Preserved } \\
\text { Hysteroscopic } \\
\text { Approach for the } \\
\text { Treatment of Stage Ia } \\
\text { Endometrioid } \\
\text { Carcinoma. }\end{array}$ & 2017 & $\begin{array}{l}\text { Estudo } \\
\text { retrospectivo }\end{array}$ & $\begin{array}{l}11 \text { mulheres } \\
\text { jovens com } \\
\text { estágio de Ia de } \\
\text { carcinoma } \\
\text { endometrioide }\end{array}$ & $\begin{array}{l}\text { Após o tratamento } \\
\text { com abordagem } \\
\text { histeroscópica combinada } \\
\text { com progesterona, } \\
9 \text { pacientes obtiveram } \\
\text { remissão completa e } \\
2 \text { pacientes obtiveram } \\
\text { remissão parcial. Os } \\
\text { resultados da citologia } \\
\text { peritoneal em } \\
4 \text { pacientes foram } \\
\text { negativos. Até o momento, } \\
\text { seis dos } 11 \text { pacientes deram à } \\
\text { luz sete bebês e um paciente } \\
\text { teve uma gravidez } \\
\text { ectópica. Dois pacientes em } \\
\text { última análise, passou por } \\
\text { ressecção radical. }\end{array}$ \\
\hline $\begin{array}{l}\text { 15. Fertility } \\
\text { preservation in } \\
\text { women with } \\
\text { borderline ovarian } \\
\text { tumors - how does it } \\
\text { impact disease } \\
\text { outcome? A cohort } \\
\text { study. }\end{array}$ & 2017 & $\begin{array}{l}\text { Estudo de } \\
\text { coorte } \\
\text { histórica }\end{array}$ & 213 pacientes & $\begin{array}{l}\text { De } 132 \text { mulheres com } 40 \text { anos } \\
\text { ou menos no momento do } \\
\text { diagnóstico, } 112(85 \%) \\
\text { tiveram um procedimento } \\
\text { de fertilidade e } 60(46 \%) \\
\text { tiveram a conservação de um } \\
\text { ovário } \\
\text { envolvido. } 50 \text { pacientes (24\%) } \\
\text { desenvolveram } \\
\text { recidivas; preservação da } \\
\text { fertilidade e estágio avançado } \\
\text { foram independentemente } \\
\text { associados com recorrência na } \\
\text { análise multivariada. } 11 \\
\text { (5\%) pacientes morreram de } \\
\text { sua doença. } \\
\text { A preservação da } \\
\text { fertilidade não foi associada à } \\
\text { sobrevida comprometida. }\end{array}$ \\
\hline $\begin{array}{l}\text { 16. Oncofertility in } \\
\text { patients with stage I } \\
\text { epithelial ovarian } \\
\text { cancer: } \\
\text { fertility-sparing } \\
\text { surgery in young } \\
\text { women of }\end{array}$ & 2017 & $\begin{array}{l}\text { Estudo de } \\
\text { coorte }\end{array}$ & $\begin{array}{l}108 \text { paciente e } \\
\text { m idade } \\
\text { reprodutiva (s } \\
40 \text { anos) } \\
\text { diagnosticados } \\
\text { com câncer } \\
\text { epitelial de } \\
\text { ovário (EOC) } \\
\text { estágio I }\end{array}$ & $\begin{array}{l}\text { O tipo de cirurgia incluiu } \\
\text { cirurgia de fertilidade (FSS) } \\
(48,1 \%) \text { e cirurgia radical } \\
\text { (RS) }(51,9 \%) \text {. } \\
\text { Observamos que o grau } 3 \text { ou o } \\
\text { carcinoma de células claras foi } \\
\text { o único fator de risco } \\
\text { independente para sobrevida } \\
\text { livre de doença e sobrevida } \\
\text { específica do tumor na análise }\end{array}$ \\
\hline
\end{tabular}




\begin{tabular}{|c|c|c|c|c|}
\hline reproductive age. & & & & $\begin{array}{l}\text { multivariada. Os } \\
\text { pacientes com carcinoma de } \\
\text { células claras ou de grau } 3 \\
\text { tenderam a ter mais de } 30 \\
\text { anos, ter endometriose e } \\
\text { serem submetidos a RS. } \\
\text { A cirurgia de fertilidade não } \\
\text { afetou a sobrevida livre de } \\
\text { doença ou a sobrevida } \\
\text { específica do tumor } \\
\text { entre pacientes em idade } \\
\text { reprodutiva com EOC de } \\
\text { estágio I e entre pacientes } \\
\text { de alto risco com estágio } \\
\text { IC2-3, grau } 3 \text { ou carcinoma de } \\
\text { células claras. }\end{array}$ \\
\hline $\begin{array}{l}\text { 17. Could } \\
\text { fertility-sparing } \\
\text { surgery be considered } \\
\text { for women with early } \\
\text { stage ovarian clear } \\
\text { cell carcinoma? }\end{array}$ & 2017 & $\begin{array}{l}\text { Estudo de } \\
\text { coorte }\end{array}$ & $\begin{array}{l}741 \text { mulheres } \\
\text { na } \\
\text { pré-menopausa } \\
\text { que foram } \\
\text { cirurgicamente } \\
\text { preparadas com } \\
\text { o diagnóstico } \\
\text { de estádio } \\
\text { unilateral IA ou } \\
\text { IC de } \\
\text { carcinoma de } \\
\text { células claras } \\
\text { de ovário } \\
\text { (OCCC) }\end{array}$ & $\begin{array}{l}\text { taxa de preservação do } \\
\text { útero foi de } 14,5 \% \text { ( } 96 / 663) \text {, } \\
\text { enquanto a taxa de } \\
\text { preservação ovariana (OP) foi } \\
\text { de } 28,1 \% \text { ( } 71 / 253) \text {. As taxas } \\
\text { de sobrevivência especificado } \\
\text { câncer (CSS) de cinco anos } \\
\text { foram de } 90,8 \% \text { para as } \\
\text { mulheres que não realizaram } \\
\text { histerectomia em comparação } \\
\text { com } 87,7 \% \text { para as que } \\
\text { fizeram. } \\
\text { Da mesma forma, as taxas de } \\
\text { CSS de } 5 \text { anos nos grupos } \\
\text { OP e salpingo-ooforectomia } \\
\text { bilateral (BSO) foram de } \\
92,6 \% \text { e } 85 \% \text {, } \\
\text { Preservação uterina e a OP } \\
\text { não tiveram impacto negativo } \\
\text { nos desfechos oncológicos }\end{array}$ \\
\hline $\begin{array}{l}\text { 18. Simple Vaginal } \\
\text { Trachelectomy: A } \\
\text { Valuable } \\
\text { Fertility-Preserving } \\
\text { Option in } \\
\text { Early-Stage } \\
\text { Cervical Cancer. }\end{array}$ & 2017 & & $\begin{array}{l}35 \text { mulheres } \\
\text { com media de } \\
\text { idade de } 29 \\
\text { anos. }\end{array}$ & $\begin{array}{l}8 \text { estavam no estágio IA1 com } \\
\text { invasão do espaço } \\
\text { linfovascular, } 9 \text { no estágio } \\
\text { IA2, e } 18 \text { no estágio } \\
\text { IB1.Houve } 1 \text { recorrência } \\
\text { tratada com quimioterapia e } \\
\text { radiação pélvica.Houveram } 25 \\
\text { mulheres que ficaram } \\
\text { grávidas. }\end{array}$ \\
\hline
\end{tabular}




\begin{tabular}{|c|c|c|c|c|}
\hline $\begin{array}{l}\text { 19. Feasibility of } \\
\text { uterine } \\
\text { preservation in the } \\
\text { management of } \\
\text { early-stage uterine } \\
\text { adenosarcomas: a } \\
\text { single institute } \\
\text { experience. }\end{array}$ & 2017 & retrospectivo & \begin{tabular}{|l}
31 pacientes \\
com \\
adenosarcoma \\
uterino em \\
estágio \\
precoce. \\
Cirurgia \\
preservadora \\
foi feita em 7 \\
mulheres.
\end{tabular} & $\begin{array}{l}\text { Das } 7 \text { pacientes que fizeram a } \\
\text { cirurgia de preservação } \\
\text { uterina, } 3 \text { mulheres não } \\
\text { mostraram evidência da } \\
\text { doença, } 2 \text { continuaram com a } \\
\text { neoplasia e } 2 \text { sobreviveram } \\
\text { depois da recorrência. No } \\
\text { grupo da cirurgia preservadora } \\
1 \text { paciente teve crescimento do } \\
\text { tumor na época do diagnótico } \\
\text { e teve a recorrência da doença. } \\
\text { No grupo da histerectomia } 3 \\
\text { das } 24 \text { pacientes tiveram } \\
\text { recorrência do tumor. }\end{array}$ \\
\hline $\begin{array}{l}\text { 20. The Safety of } \\
\text { Ovarian } \\
\text { Preservation in } \\
\text { Stage I Endometrial } \\
\text { Endometrioid } \\
\text { Adenocarcinoma } \\
\text { Based on } \\
\text { Propensity Score } \\
\text { Matching. }\end{array}$ & 2017 & retrospectivo & \begin{tabular}{|l} 
Um total de \\
7183 pacientes \\
foram \\
identificadas e \\
a preservação \\
ovariana foi \\
realizada em \\
863 pacientes. \\
Diagnóstico de \\
adenocarcinom \\
a endometrial \\
em mulheres \\
com 50 anos ou \\
mais novas. \\
\end{tabular} & $\begin{array}{l}\text { Depois da análise de todos os } \\
\text { dados as diferenças de todas } \\
\text { as características entre a } \\
\text { preservação ovariana e a } \\
\text { ooforectomia não foram } \\
\text { significantes. Preservacão } \\
\text { ovariana não teve efeito na } \\
\text { mortalidade especifica do } \\
\text { câncer nem com a } \\
\text { sobrevivência. }\end{array}$ \\
\hline $\begin{array}{l}21 . \text { Analysis of } \\
\text { outcomes and } \\
\text { prognostic factors } \\
\text { after fertility-sparing } \\
\text { surgery in } \\
\text { malignant ovarian } \\
\text { germ cell tumors. }\end{array}$ & 2017 & retrospectivo & $\begin{array}{l}171 \text { pacientes } \\
\text { que fizeram a } \\
\text { cirurgia que } \\
\text { preserva a } \\
\text { fertilidade. }\end{array}$ & $\begin{array}{l}25 \text { pacientes tiveram } \\
\text { recorrência da doença e } 5 \\
\text { pacientes morreram num } \\
\text { período de } 86 \text { meses. No } \\
\text { período de } 5 \text { anos de } \\
\text { sobrevivência sem a doença } \\
\text { foi de } 86 \% \text { e a sobrevivência } \\
\text { geral foi de } 97 \% \text {. A cirurgia } \\
\text { preservadora da fertilidade } \\
\text { teve excelentes taxas de } \\
\text { sobrevivência em mulheres } \\
\text { jovens com tumores malignos } \\
\text { de ovário mesmo que em } \\
\text { estagio avançado. }\end{array}$ \\
\hline
\end{tabular}




\begin{tabular}{|c|c|c|c|c|}
\hline $\begin{array}{l}\text { 22. Fertility-Sparing } \\
\text { Surgery Should Be } \\
\text { the Standard } \\
\text { Treatment in } \\
\text { Patients with } \\
\text { Malignant Ovarian } \\
\text { Germ Cell Tumors. }\end{array}$ & 2017 & retrospectivo & $\begin{array}{l}69 \text { pacientes } \\
\text { com estágio } 1 \mathrm{e} \\
2 \text { de tumores } \\
\text { malignos } \\
\text { ovarianos de } \\
\text { células } \\
\text { germinativas. }\end{array}$ & $\begin{array}{l}\text { Idade média de } 21 \text { anos. } \\
\text { Tamanho médio do tumor de } \\
150 \text { mm. Tipo da cirugia } \\
\text { (conservadora vs } \\
\text { convencional) e } \\
\text { linfadenectomia ( feita vs não } \\
\text { feita) foi insignificante para a } \\
\text { recorrência. Entretanto } \\
\text { desfecho cirúrgico e tipo de } \\
\text { tumor foi determinante na } \\
\text { decorrência. }\end{array}$ \\
\hline $\begin{array}{l}\text { 23. Does hormonal } \\
\text { therapy for fertility } \\
\text { preservation affect } \\
\text { the survival of } \\
\text { young women with } \\
\text { early-stage } \\
\text { endometrial } \\
\text { cancer? }\end{array}$ & 2017 & coorte & $\begin{array}{l}6339 \text { mulheres } \\
\text { com câncer de } \\
\text { endométrio de } \\
\text { baixo grau } \\
\text { localizado com } \\
\text { menos de } 45 \\
\text { anos. }\end{array}$ & $\begin{array}{l}161 \text { receberam inicialmente } \\
\text { hormônio-terapia e } 6178 \\
\text { cirurgia primária. Depois de } \\
15 \text { anos de seguimento as } \\
\text { causas gerais de mortalidade } \\
\text { não diferiram nos grupos. } \\
\text { Mortalidade especifica de } \\
\text { câncer foi maior nas pacientes } \\
\text { tratadas com } \\
\text { hormônio-terapia. Pacientes } \\
\text { jovens com baixo grau de } \\
\text { câncer endometrial tiveram } \\
\text { altos níveis de sobrevivência } \\
\text { independentemente do } \\
\text { tratamento realizado. }\end{array}$ \\
\hline $\begin{array}{l}\text { 24. Fertility-sparing } \\
\text { surgery for patients } \\
\text { with low-grade } \\
\text { endometrial stromal } \\
\text { sarcoma }\end{array}$ & 2017 & retrospectivo & $\begin{array}{l}17 \text { pacientes } \\
\text { com estágio } 1 \\
\text { baixo grau de } \\
\text { sarcoma } \\
\text { endometrial } \\
\text { stromal } \\
\text { tratadas com } \\
\text { cirurgia } \\
\text { poupadora da } \\
\text { fertilidade }\end{array}$ & $\begin{array}{l}\text { Hormônio terapia adjuvante } \\
\text { foi realizada em } 15 \\
\text { pacientes. } 10 \text { pacientes tiveram } \\
\text { recorrência. Todas as } 10 \\
\text { tinham câncer estagio } 1 \mathrm{~B} \text {. } \\
\text { Todas as } 17 \text { pacientes estavam } \\
\text { vivas e sem a doença no } \\
\text { último contato. Depois do } \\
\text { tratamento } 5 \text { de } 8 \text { pacientes } \\
\text { que tentaram engravidar } \\
\text { obtiveram sucesso. }\end{array}$ \\
\hline
\end{tabular}




\begin{tabular}{|c|c|c|c|c|}
\hline $\begin{array}{l}\text { 25. Long-term } \\
\text { results of } \\
\text { fertility-sparing } \\
\text { treatment } \\
\text { compared with } \\
\text { standard radical } \\
\text { surgery for } \\
\text { early-stage } \\
\text { epithelial ovarian } \\
\text { cancer. }\end{array}$ & 2016 & $\begin{array}{l}\text { Análise } \\
\text { retrospectiva }\end{array}$ & $\begin{array}{l}1031 \text { pacientes } \\
\text { com cancer } \\
\text { ovariano } \\
\text { precoce }\end{array}$ & $\begin{array}{l}242 \text { com cirurgia poupadora } \\
\text { da fertilidade e } 789 \text { com a } \\
\text { cirurgia radical. O tipo de } \\
\text { tratamento não influenciou na } \\
\text { sobrevivência especifica do } \\
\text { câncer. Foi achada } \\
\text { significativa associação entre } \\
\text { tumores de baixo grau e idade } \\
\text { jovem. }\end{array}$ \\
\hline $\begin{array}{l}\text { 26. Fertility } \\
\text { Preservation Is } \\
\text { Safe for Serous } \\
\text { Borderline Ovarian } \\
\text { Tumors. }\end{array}$ & 2016 & retrospectivo & $\begin{array}{l}132 \text { pacientes } \\
\text { com tumor } \\
\text { ovariano seroso } \\
(\mathrm{BOT})\end{array}$ & $\begin{array}{l}45 \% \text { tinham } 40 \text { anos ou } \\
\text { menos, } 42 \text { receberam cirurgia } \\
\text { preservadora da fertilidade, } 18 \\
\text { tiveram recorrência. O risco } \\
\text { de recorrência foi maior nas } \\
\text { pacientes com } 40 \text { anos ou } \\
\text { menos na cirurgia poupadora } \\
\text { comparada a cirurgia radical }\end{array}$ \\
\hline $\begin{array}{l}\text { 27. Outcomes of } \\
\text { fertility-sparing } \\
\text { surgery among } \\
\text { young women with } \\
\text { FIGO stage I clear } \\
\text { cell carcinoma of } \\
\text { the ovary. }\end{array}$ & 2016 & retrospectivo & $\begin{array}{l}47 \text { pacientes } \\
\text { com } 45 \text { anos ou } \\
\text { menos que } \\
\text { tinham } \\
\text { carcinoma de } \\
\text { ovário grau } 1 .\end{array}$ & $\begin{array}{l}22 \text { fizeram a cirurgia } \\
\text { preservadora da fertilidade e } \\
25 \text { a cirurgia radical. } 5 \\
\text { pacientes de cada grupo } \\
\text { tiveram a recorrência da } \\
\text { doença. Não houveram } \\
\text { diferenças de sobrevivência } \\
\text { ou de presença da doença em } \\
5 \text { anos. }\end{array}$ \\
\hline $\begin{array}{l}\text { 28. Laparoscopic } \\
\text { fertility-sparing } \\
\text { surgery for early } \\
\text { ovarian epithelial } \\
\text { cancer: A } \\
\text { multi-institutional } \\
\text { experience. }\end{array}$ & 2016 & coorte & $\begin{array}{l}65 \text { mulheres } \\
\text { com estagio } \\
\text { precoce de } \\
\text { câncer } \\
\text { ovariano. Idade } \\
\text { média de } 33 \\
\text { anos }\end{array}$ & $\begin{array}{l}36 \text { de baixo risco (IAG1-2) E } \\
29 \text { de alto risco (IAG3 ou } \\
\text { maior). A taxa de } \\
\text { sobrevivência geral foi de } \\
95.4 \% \text { e sobrevivência livre } \\
\text { da recorrência foi de } 84.6 \%\end{array}$ \\
\hline $\begin{array}{l}\text { 29. Fertility-sparing } \\
\text { surgery for young } \\
\text { patients with } \\
\text { borderline ovarian } \\
\text { tumors (BOTs): } \\
\text { single institution } \\
\text { experience }\end{array}$ & 2016 & & $\begin{array}{l}122 \text { paciente } \\
\text { com tumors de } \\
\text { ovário } \\
\text { borderline }\end{array}$ & $\begin{array}{l}4 \text { tipos de cirurgia poupadora } \\
\text { da fertilidade foram } \\
\text { realizadas. A taxa subsequente } \\
\text { de fertilidade foi maior na } \\
\text { laparoscopia do que no grupo } \\
\text { da laparotomia. A cirurgia } \\
\text { poupadora é segura e benéfica } \\
\text { para a maioria dos BOTs. }\end{array}$ \\
\hline
\end{tabular}




\begin{tabular}{|l|l|l|l|l|}
\hline $\begin{array}{l}\text { 30. Outcomes of } \\
\text { laparoscopic } \\
\text { fertility-sparing } \\
\text { surgery in clinically } \\
\text { early-stage } \\
\text { epithelial ovarian } \\
\text { cancer. }\end{array}$ & 2016 & $\begin{array}{l}18 \text { pacientes } \\
\text { com media de } \\
\text { idade de 33,5 } \\
\text { anos }\end{array}$ & $\begin{array}{l}\text { Houveram 7,5,3 e 3 pacientes } \\
\text { com tipos de tumores mucoso, } \\
\text { endometrióide, células clear e } \\
\text { seroso respectivamente. Não } \\
\text { houve complicação cirúrgica. } \\
4 \text { mulheres engravidaram após } \\
\text { o tratamento. }\end{array}$ \\
& & & \\
\end{tabular}

\begin{tabular}{|c|c|c|c|}
\hline $\begin{array}{l}31 . \text { Fertility-sparing } \\
\text { surgical } \\
\text { management of } \\
\text { ovarian cancer. }\end{array}$ & 2015 & $\begin{array}{l}43 \text { mulheres com } \\
\text { cancer ovariano } \\
\text { localizado }\end{array}$ & $\begin{array}{l}\text { Não houveram casos de } \\
\text { recorrência. } 14 \text { engravidaram } \\
\text { e } 2 \text { destas abortaram antes de } \\
22 \text { semanas, } 1 \text { teve um parto } \\
\text { com } 34 \text { semanas de gestação. } \\
\text { Em outro grupo } 9 \text { mulheres } \\
\text { engravidaram e } 1 \text { destas } \\
\text { abortou com } 10 \text { semanas de } \\
\text { gestação, } 1 \text { teve um caso } \\
\text { óbito intrauterino fetal com } \\
27 \text { semanas }\end{array}$ \\
\hline
\end{tabular}

\begin{tabular}{|c|c|c|c|c|}
\hline $\begin{array}{l}\text { 32. Utilization and } \\
\text { Outcomes of } \\
\text { Ovarian } \\
\text { Conservation in } \\
\text { Premenopausal } \\
\text { Women With } \\
\text { Endometrial } \\
\text { Cancer. }\end{array}$ & 2016 & coorte & $\begin{array}{l}15648 \text { mulheres } \\
\text { (1121 tiveram } \\
\text { preservacão } \\
\text { ovariana } \\
14527 \\
\text { ooforectomia }\end{array}$ & $\begin{array}{l}\text { Preservacão ovariana foi } \\
\text { mais comum em mulheres } \\
\text { jovens, negras com tumores } \\
\text { de baixo grau e em estágios } \\
\text { precoces. A cirurgia em } \\
\text { questão não afeta a } \\
\text { sobrevivência em mulheres } \\
\text { jovens com câncer } \\
\text { endometrial }\end{array}$ \\
\hline
\end{tabular}




\begin{tabular}{|c|c|c|c|c|}
\hline $\begin{array}{l}\text { 33. Cancer } \\
\text { Incidence in } \\
\text { Patients with } \\
\text { Atypical } \\
\text { Endometrial } \\
\text { Hyperplasia } \\
\text { Managed by } \\
\text { Primary } \\
\text { Hysterectomy or } \\
\text { Fertility-sparing } \\
\text { Treatment. }\end{array}$ & 2015 & $\begin{array}{l}\text { retrospectiv } \\
\text { o }\end{array}$ & $\begin{array}{l}\text { 111 pacientes } \\
\text { com } \\
\text { hyperplasia } \\
\text { endometrial } \\
\text { atípica. } \\
\text { grupos: } \\
\text { pacientes } \\
\text { submetidos a } \\
\text { cirurgia } \\
\text { poupadora da } \\
\text { fertilidade e } \\
\text { outro grupo } \\
\text { submetido a } \\
\text { histerectomia }\end{array}$ & $\begin{array}{l}\text { A cirurgia poupadora não } \\
\text { aumenta o risco de } \\
\text { diagnosticar } \\
\text { endometrial. }\end{array}$ \\
\hline
\end{tabular}

\begin{tabular}{|c|c|c|c|c|}
\hline $\begin{array}{l}\text { 34. Long-term } \\
\text { outcomes of } \\
\text { fertility-sparing } \\
\text { treatment of atypical } \\
\text { polypoid } \\
\text { adenomyoma with } \\
\text { medroxyprogesteron } \\
\text { e acetate. }\end{array}$ & 2016 & retrospectivo & $\begin{array}{l}18 \text { pacientes com } \\
\text { adenomioma } \\
\text { polipóide atípico } \\
\text { com uso de acetate } \\
\text { de } \\
\text { medroxiprogesteron } \\
\text { a }\end{array}$ & $\begin{array}{l}\text { Depois do tratamento } \\
14 \quad \text { pacientes } \\
\text { atintigiram resposta } \\
\text { total ou parcial, } 8 \\
\text { tiveram recorrência e } \\
4 \text { permaneceram com } \\
\text { a doença. } 10 \text { foram } \\
\text { eventualmente } \\
\text { submetidas a } \\
\text { histerectomia. }\end{array}$ \\
\hline
\end{tabular}

\section{DISCUSSÃO}

Calcula-se que, anualmente, 650 mil mulheres são atingidas por câncer ginecológico invasivo e dessas $8 \%$ têm menos de 40 anos, sendo a cada ano mais mulheres jovens acometidas ${ }^{21}$. As opções para o tratamento do câncer ginecológico são a quimioterapia, radioterapia e as cirurgias radicais totais ${ }^{1}$.

Durante o tratamento, a radioterapia, quando for em região pélvica, poderá danificar os ovários, dependendo do tamanho e da localização do tumor e da intensidade da irradiação utilizada ${ }^{3}$. O mesmo pode ocorrer com a quimioterapia, dependendo das drogas utilizadas e das doses necessárias para a cura da doença, poderá prejudicar também a função ovariana ${ }^{32}$. As cirurgias radicais totais são, em sua maioria, a melhor opção; o que pode macular o futuro fértil destas mulheres ${ }^{23}$. 
Os estudos destacaram como sendo os principais métodos para preservação da fertilidade feminina a cirurgia conservadora e o manejo poupador de fertilidade hormonal. Onde 26 artigos descreveram a cirurgia conservadora como técnica alternativa à histerectomia e ooforectomia bilateral em pacientes jovens. E outros 8 artigos apontaram como manejo poupador de fertilidade hormonal, o uso de progesterona oral (acetato de medroxiprogesterona (MPA) ou acetato de megestrol (MA)), para menor impacto sobre a fertilidade, sendo esse menos invasivo, porém, se for tolerado pela paciente os efeitos colaterais; além de haver diagnóstico precoce do câncer para ser instituído ${ }^{33}$.

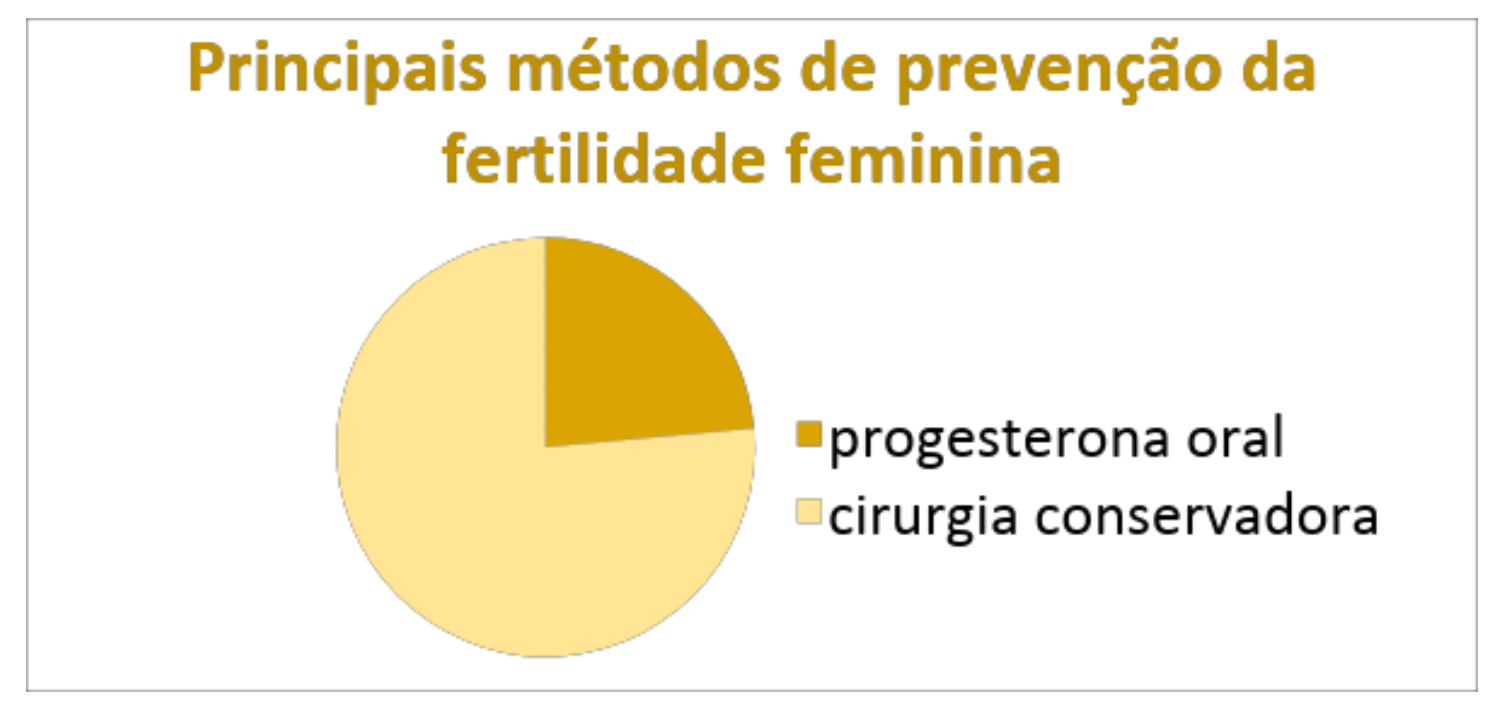

\section{CONCLUSÃO:}

Apesar do avanço das técnicas de tratamento do câncer ginecológico com maior probabilidade de cura nos últimos anos; o diagnóstico precoce é fundamental para o sucesso da preservação da fertilidade feminina. Foi possível identificar que 46,43\% foi a taxa de sucesso para gestações pós tratamento oncológico ${ }^{1^{\circ}}$, desde que associada ao diagnóstico precoce e sem associação à diminuição da sobrevida das pacientes quando utilizado métodos como cirurgia conservadora ou tratamento hormonal com MPA ou $\mathrm{MA}^{2 \circ}$.

\section{REFERÊNCIAS:}

1. NOMURA, Hidetaka et al. Maintenance hormonal therapy after treatment with medroxyprogesterone acetate for patients with atypical polypoid adenomyoma. Japanese Journal Of Clinical Oncology, [s.1.], v. 48, n. 3, p.255-258, 17 jan. 2018. Oxford University Press (OUP). http://dx.doi.org/10.1093/jjco/hyx193.

2. DITTO, Antonino et al. Long-term safety of fertility sparing surgery in early stage ovarian cancer: Comparison to standard radical surgical procedures. Gynecologic Oncology, [s.1.], v. 138, n. 1, p.78-82, jul. 2015. Elsevier BV. http://dx.doi.org/10.1016/j.ygyno.2015.05.004. 
3. HELPMAN, Limor et al. Safety of ovarian conservation and fertility preservation in advanced borderline ovarian tumors. Fertility And Sterility, [s.1.], v. 104, n. 1, p.138-144, jul. 2015. Elsevier BV. ttp://dx.doi.org/10.1016/j.fertnstert.2015.03.038

4. SOUZA, Elen et al. Preservação da fertilidade e dos ovários em mulheres com tumores anexiais benignos. Revista Brasileira de Ginecologia e Obstetrícia, [s.1.], v. 37,

n. 1 p.36-41, jan. 2015. FapUNIFESP (SciELO). ttp://dx.doi.org/10.1590/so100-720320140005179.

5. LYU, Jiangtao; SUN, Tingting; TAN, Xianjie. Ovarian Preservation in Young Patients With Stage I Cervical Adenocarcinoma. International Journal Of Gynecological Cancer, [s.1.], v. 24, n. 8, p.1513-1520, out. 2014. Ovid Technologies (Wolters Kluwer Health). http://dx.doi.org/10.1097/igc.0000000000000231.

6. HENES, Melanie et al. Possibilities of Fertility Preservation in Young Patients with Ovarian Cancer. Anticancer Research, Abu Dhabi, Emirados Árabes, v. 34, n. 7, p.38513854, maio 2014.

7. WANG, Chin-jung et al. Fertility-Preserving Treatment in Young Women With Endometrial Adenocarcinoma. International Journal Of Gynecological Cancer, [s.l.], v. 24, n. 4, p.718-728, maio 2014. Ovid Technologies (Wolters Kluwer Health). ttp://dx.doi.org/10.1097/igc.0000000000000098.

8. FAKHR, Ibrahim et al. Outcome of fertility preserving surgery in early stage ovarian cancer. Journal Of The Egyptian National Cancer Institute, [s.1.], v. 25, n. 4, p.219-222, dez. 2013. Elsevier BV. ttp://dx.doi.org/10.1016/j.jnci.2013.07.003.

9. PARLAKGUMUS, Huriye Ayse et al. Fertility outcomes of patients with early stage endometrial carcinoma. Journal Of Obstetrics And Gynaecology Research, [s.1.], v. 40, n. 1, p.102-108, 5 set. 2013. Wiley. ttp://dx.doi.org/10.1111/jog.12132.

10. SUN, Chaoyang et al. Safety of ovarian preservation in young patients with earlystage endometrial cancer: a retrospective study and meta-analysis. Fertility And Sterility, [s.1.], v. 100, n. 3, p.782-787, set. 2013. Elsevier BV. ttp://dx.doi.org/10.1016/j.fertnstert.2013.05.032.

11. FANG, Liu et al. [A retrospective study of tumor and fertility outcomes after fertilitysparing surgical treatment of patients with borderline ovarian tumors]. Jornal Médico Chinês, China, v. 97, n. 47, p.3699-3703, dez. 2017.

12. NASIOUDIS, Dimitrios et al. Fertility-preserving surgery for advanced stage ovarian germ cell tumors. Gynecologic Oncology, [s.1.], v. 147, n. 3, p.493-496, dez. 2017. Elsevier BV. http://dx.doi.org/10.1016/j.ygyno.2017.10.010.

13. NASIOUDIS, Dimitrios et al. Safety of Fertility-Sparing Surgery for Premenopausal Women With Sex Cord-Stromal Tumors Confined to the Ovary. International Journal Of Gynecological Cancer, [s.1.], v. 27, n. 9, p.1826-1832, nov. 
2017. Ovid Technologies (Wolters Kluwer Health). http://dx.doi.org/10.1097/igc.0000000000001110.

14. WANG, Fangfang et al. Fertility Preserved Hysteroscopic Approach for the Treatment of Stage Ia Endometrioid Carcinoma. International Journal Of Gynecological Cancer, [s.1.], v. 27, n. 9, p.1919-1925, nov. 2017. Ovid Technologies (Wolters Kluwer Health). http://dx.doi.org/10.1097/igc.0000000000001109.

15. HELPMAN, Limor et al. Fertility preservation in women with borderline ovarian tumors - how does it impact disease outcome? A cohort study. Acta Obstetricia Et Gynecologica Scandinavica, [s.1.], v. 96, n. 11, p.1300-1306, 21 set. 2017. Wiley. ttp://dx.doi.org/10.1111/aogs.13203.

16. JIANG, Xuan et al. Oncofertility in patients with stage I epithelial ovarian cancer: fertility-sparing surgery in young women of reproductive age. World Journal Of Surgical Oncology, [s.1.], v. 15, n. 1, p.1-11, 15 ago. 2017. Springer Nature. http://dx.doi.org/10.1186/s12957-017-1222-4.

17. NASIOUDIS, imitrios et al. Could fertility-sparing surgery be considered for women with early stage ovarian clear cell carcinoma? Journal Of Gynecologic Oncology, [s.l.], v. 28, n. 6, p.1-10, 2017. Asian Society of Gynecologic Oncology; Korean Society of Gynecologic Oncology and Colposcopy (KAMJE). ttp://dx.doi.org/10.3802/jgo.2017.28.e71.

18. PLANTE, Marie et al. Simple Vaginal Trachelectomy. International Journal Of Gynecological Cancer, [s.1.], v. 27, n. 5, p.1021-1027, jun. 2017. Ovid Technologies (Wolters Kluwer Health). http://dx.doi.org/10.1097/igc.0000000000000989.

19. LEE, Young-jae et al. Feasibility of uterine preservation in the management of earlystage uterine adenosarcomas: a single institute experience. World Journal Of Surgical Oncology, [s.1.], v. 15, n. 1, p.1-5, 19 abr. 2017. Springer Nature. http://dx.doi.org/10.1186/s12957-017-1137-0.

20. HOU, Ting et al. The Safety of Ovarian Preservation in Stage I Endometrial Endometrioid Adenocarcinoma Based on Propensity Score Matching. Combinatorial Chemistry \& High Throughput Screening, [s.1.], v. 20, n. 7, 23 out. 2017. Bentham Science Publishers Ltd.. http://dx.doi.org/10.2174/1386207320666170417145856.

21. PARK, Jeong-yeol et al. Analysis of outcomes and prognostic factors after fertilitysparing surgery in malignant ovarian germ cell tumors. Gynecologic Oncology, [s.1.], v. 145, n. 3, p.513-518, jun. 2017. Elsevier BV. http://dx.doi.org/10.1016/j.ygyno.2017.03.023.

22. TURKMEN, Osman et al. Fertility-Sparing Surgery Should Be the Standard Treatment in Patients with Malignant Ovarian Germ Cell Tumors. Journal Of Adolescent And Young Adult Oncology, [s.1.], v. 6, n. 2, p.270-276, jun. 2017. Mary Ann Liebert Inc. http://dx.doi.org/10.1089/jayao.2016.0086. 
23. GREENWALD, Zoë R. et al. Does hormonal therapy for fertility preservation affect the survival of young women with early-stage endometrial cancer? Cancer, [s.l.], v. 123, n. 9, p.1545-1554, 27 dez. 2016. Wiley. http://dx.doi.org/10.1002/cncr.30529.

24. XIE, Weimin et al. Fertility-sparing surgery for patients with low-grade endometrial stromal sarcoma. Oncotarget, [s.1.], v. 8, n. 6, 6 out. 2016. Impact Journals, LLC. http://dx.doi.org/10.18632/oncotarget.12491.

25. FRUSCIO, Robert et al. Long-term results of fertility-sparing treatment compared with standard radical surgery for early-stage epithelial ovarian cancer. British Journal Of Cancer, [s.1.], v. 115, n. 6, p.641-648, 18 ago. 2016. Springer Nature. ttp://dx.doi.org/10.1038/bjc.2016.254.

26. VANCRAEYNEST, Eveline et al. Fertility Preservation Is Safe for Serous Borderline Ovarian Tumors. International Journal Of Gynecological Cancer, [s.1.], v. 26, n. 8, p.1399-1406, out. 2016. Ovid Technologies (Wolters Kluwer Health). http://dx.doi.org/10.1097/igc.0000000000000782.

27. PARK, Jeong-yeol et al. Outcomes of fertility-sparing surgery among young women with FIGO stage I clear cell carcinoma of the ovary. International Journal Of Gynecology \& Obstetrics, [s.1.], v. 134, n. 1, p.49-52, 11 mar. 2016. Wiley. http://dx.doi.org/10.1016/j.ijgo.2015.10.022.

28. GHEZZI, Fabio et al. Laparoscopic fertility-sparing surgery for early ovarian epithelial cancer: A multi-institutional experience. Gynecologic Oncology, [s.1.], v. 141, n. 3, p.461-465, jun. 2016. Elsevier BV. http://dx.doi.org/10.1016/j.ygyno.2016.03.030.

29. CHEN, Rui-fang et al. Fertility-sparing surgery for young patients with borderline ovarian tumors (BOTs): single institution experience. Journal Of Ovarian Research, [s.1.], v. 9, n. 1, 18 mar. 2016. Springer Nature. ttp://dx.doi.org/10.1186/s13048-016-0226-y.

30. PARK, Jin-young et al. Outcomes of laparoscopic fertility-sparing surgery in clinically early-stage epithelial ovarian cancer. Journal Of Gynecologic Oncology, [s.l.], v. 27, n. 2, p.1-10, 2016. Asian Society of Gynecologic Oncology; Korean Society of Gynecologic Oncology and Colposcopy (KAMJE). http://dx.doi.org/10.3802/jgo.2016.27.e20.

31. BASTA, P et al. [Fertility-sparing surgical management of ovarian cancer]. Ginekol, Polônia, v. 86, n. 10, p.759-764, out. 2015.

32. WRIGHT, Jason D. et al. Utilization and Outcomes of Ovarian Conservation in Premenopausal Women With Endometrial Cancer. Obstetrics \& Gynecology, [s.l.], v. 127, n. 1, p.101-108, jan. 2016. Ovid Technologies (Wolters Kluwer Health). ttp://dx.doi.org/10.1097/aog.0000000000001181. 
33. GONTHIER, $\mathrm{C}$ et al. Cancer Incidence in Patients with Atypical Endometrial Hyperplasia Managed by Primary Hysterectomy or Fertility-sparing Treatment. Anticancer Res, França, v. 12, n. 35, p.6799-6804, dez. 2015.

34. NOMURA, Hidetaka et al. Long-term outcomes of fertility-sparing treatment of atypical polypoid adenomyoma with medroxyprogesterone cetate. Archives Of Gynecology And Obstetrics, [s.1.], v. 293, n. 1, p.177-181, 26 jul. 2015. Springer Nature. http://dx.doi.org/10.1007/s00404-015-3824-9. 